\title{
Comparing Classroom Problem-Solving with No Feedback to Web-Based Homework Assistance
}

\author{
Leena Razzaq ${ }^{1}$, Michael Mendicino ${ }^{2}$ and Neil T. Heffernan ${ }^{1}$ \\ ${ }^{1}$ Worcester Polytechnic Institute \\ Worcester, Massachusetts 01609 \\ \{leenar, nth\}@cs.wpi.edu \\ ${ }^{2}$ West Virginia University \\ Morgantown, West Virginia 26506 \\ mmendic1@mail.wvu.edu
}

\begin{abstract}
It is common for math teachers to give students time in class to practice problem solving skills. Some studies have shown that intelligent tutoring systems (ITS) can be superior to traditional classroom instruction. In this study, we compare problem solving with little or no feedback in the classroom to problem solving using a web-based ITS for homework. The system provides students with coached practice that is meant to scaffold "learning by doing" while students practice their problem solving skills. We found evidence that using the web-based ITS to practice problem solving at home was better than the classroom problem solving with an effect size of 0.5 .
\end{abstract}

Key Words: Problem-solving, intelligent tutoring systems, symbolization, webbased homework, word problems

\section{Introduction}

Many studies have shown that learning can be improved by learning technologies with varying effect sizes depending on the system and the metrics used to measure learning. It has been shown that traditional computer-assisted instructional systems (CAI) can lead to better learning when compared to traditional classroom instruction $[1,2]$. Kulik \& Kulik's [1] studies indicate that CAI systems can lead to about 0.3 to 0.5 standard deviation effect sizes over classroom instruction and suggests that classrooms using CAI systems can learn more and learn faster than classrooms using traditional classroom instruction alone.

Evidence of the benefits of newer intelligent tutoring systems (ITS) over classroom instruction exists as well [3, 4]. Koedinger et al. [4] compared a commercially available ITS (Cognitive Tutors) to a classroom control and suggested a 1.0 standarddeviation effect size for experimenter-designed metrics, while for external metrics (The Iowa Algebra Aptitude test and a subset of the Math SAT) the study found an effect size of 0.3. This study may suffer from a confound of the effect of the ITS with a new textbook prepared to go along with the curriculum. It is unclear how to compare these effect sizes with the Kulik \& Kulik [1] effect size of about 0.4 as we 
don't know if the metrics in the Kulik \& Kulik studies are more generally like externally designed measures or experimenter defined measures. In another study, VanLehn et al. [5] compared an ITS not to classroom instruction, but to doing homework in a traditional paper-and-pencil manner. They found results similar to the Cognitive Tutor results mentioned above with effect sizes of about 1.0 standard deviation for their own measures, and about 0.4 for what they consider analogue to externally designed measures. Additionally, other studies have shown that ITS can produce superior learning results when compared to CAI systems [6, 7, 8].

It is common for math teachers to give students time in class to practice problem solving skills where they receive little or no feedback on their work. We question whether it is more effective to instead do web-based intelligent tutoring homework to practice problem-solving skills. In this study, we compare two conditions: problemsolving practice in the classroom and problem-solving practice for homework using an ITS. The ITS, called Ms. Lindquist, was developed by Heffernan \& Koedinger [9] and is described in the next section.

We conduct this study in a mathematics classroom while teaching the skill of writing algebra expressions for word problems, a skill we call symbolization. We report on an experiment, with one teacher and a total of 28 students. The study involved analyzing the amount of learning gains by students as measured by experimenter designed pre- and post-tests the days before and after the treatments.

\section{Web-Based Homework Assistance}

Web-based systems that allow students to do their homework online such as Blackboard (www.blackboard.com), WebCT (www.webct.com), Homework Service (https://hw.utexas.edu/bur/overview.html) and WeBWorK (http://webwork.rochester.edu) are becoming widely used at the college level. Use of homework assistance systems at the K-12 level, such as Study Island (studyisland.com) and PowerSchool (powerschool.com), is less common, but they are gaining popularity among teachers.

Advantages of web-based homework assistance systems are immediate feedback to students and automatic grading for instructors. Automatic grading can be helpful to teachers by saving time for those who do not have time to grade all of their students' paper-and-pencil homework carefully by hand, which in turn can prompt students to take homework more seriously because they know it will be graded and the grade will be recorded. Students can get immediate feedback on their answers to problems and sometimes hints or intelligent help towards solving problems.

Although there are benefits to using these web-based homework assistance systems, there can be disadvantages, as well. Many of these systems require students to enter a single answer for each problem and they do not consider or take note of students' work. Students may also try to do more math in their heads and do less scrap work which can help them to be more organized. Teachers may spend less time looking at their students' work and figuring out exactly where they are having difficulties. Because these systems often do not consider student work, it may be easier for students to cheat. Additionally, the digital divide, which may be more 
prevalent at the K-12 level than at the college level, could also prevent teachers from taking advantage of web-based homework assistance.

Research has shown positive results for using intelligent tutors instead of doing traditional paper-and-pencil homework. "MasteringPhysics" is a web-based physics homework tutor developed at MIT that uses mastery learning to help students reach mastery when solving physics homework problems. Students can request hints on problems and can receive feedback on common student errors. Warnakulasooriya \& Pritchard [10] found that twice as many students were able to complete a set of problems in a given time with the help provided with MasteringPhysics when compared to students that worked on the problems without help (administered by MasteringPhysics but without hints or feedback).

Quantum Tutors (http://www.quantumsimulations.com/) is a web-based system that is commercially available for students to do homework in the sciences and math. Students can choose topics to work on, enter their own problems and choose from a list of questions they may have on particular problems. For instance, students working on percents can choose "I need to find the percentage one number is of another" and solve problems provided by the system or enter their own values to solve. They can also choose from a list of questions such as "Why would I want to convert a percent to a fraction?" In a press release, Quantum Tutors describes a week-long study done in 2005 (http://www.quantumsimulations.com/news15.html), where students using Quantum Tutors for homework in a high school chemistry course outperformed a control group that did paper-and-pencil homework on a post-test by just over a full letter grade. The difference between groups became larger as the problems increased in difficulty.

The previously mentioned VanLehn work [5], the Andes system, is an intelligent tutoring system that provides support for problem-solving for physics homework. Andes requires students to complete whole derivations step-by-step and offers feedback after each step. Students can also ask for hints on each step to find out the nature of their errors (What's Wrong Help) or to get help on what the next step is (Next Step Help). Andes was used and evaluated in introductory physics classes from 1999 - 2003 at the U.S. Naval Academy. VanLehn et al. [5] presented evidence that students who used Andes for homework got significantly higher exam scores than students in control groups who did paper-and-pencil homework. Other studies of webbased physics homework vs. paper-and-pencil homework did not find significant differences between the two $[11,12]$.

Ms. Lindquist. Heffernan and Koedinger [9] developed an ITS, called Ms. Lindquist, which uses dialog to help students write algebra expressions by modeling both student behavior and tutorial behavior. Ms. Lindquist combines a cognitive model of student behavior in the domain of symbolization with a tutorial model of strategies observed in a human tutor. The cognitive student model has a set of production rules that models the problem solving skills needed to write algebraic expressions. The tutorial model is based on the observation of an experienced human tutor during an hour-long tutoring session and thus captures tutorial strategies that were observed to be effective for human tutors. The tutor, a middle school mathematics teacher with four years of mathematics teaching experience, had two years of one-on-one tutoring experience as well (through both University tutoring centers and private tutoring). This tutor 
charged clients 40 dollars an hour. The tutor worked with a seventh grade student whom she had not previously tutored on a list of symbolization problems. The session was recorded on video and then transcribed. Strategies that the tutor used often and that were easy to implement were chosen to implement in Ms. Lindquist's tutorial model. Table 1 shows a portion of the human tutor's transcript and Ms. Lindquist's attempt to model it.

Table 1. An experienced tutor's transcript and Ms. Lindquist's attempt to model it

\begin{tabular}{|c|c|}
\hline $\begin{array}{l}\text { Experienced Human Tutor Exact } \\
\text { Transcript }\end{array}$ & $\begin{array}{l}\text { The Ms. Lindquist Tutor Similar } \\
\text { simulated input. }\end{array}$ \\
\hline $\begin{array}{l}\text { 240. Student: [reads the "bike-trip" } \\
\text { problem] } \\
\text { Cathy took a "m" mile bike ride. She rode } \\
\text { at a speed of "s" miles per hour. She } \\
\text { stopped for a "b" hour break. Write an } \\
\text { expression for how long the trip took. }\end{array}$ & $\begin{array}{l}\text { T1: [The "bike-trip" problem was } \\
\text { presented.] } \\
\text { Please write an expression for the total } \\
\text { time the trip took. }\end{array}$ \\
\hline 241. S: um ... [Writes "s/m+b"] & $\mathrm{S} 1: \mathrm{s} / \mathrm{m}+\mathrm{b}$ \\
\hline $\begin{array}{l}\text { 242. Tutor: How do you calculate the } \\
\text { amount of time it takes you? } \\
\text { If you're, if you're, if you're riding at ... } \\
\text { Let's make it simple. If you are riding at } \\
20 \text { miles per hour, OK, and you go } 100 \\
\text { miles, how many hours did that take you? }\end{array}$ & $\begin{array}{l}\text { T2: No. Let me ask you an easier } \\
\text { question. } \\
\text { Please compute the time actually on the } \\
\text { bikes if the speed was } 20 \text { miles per } \\
\text { hour, and the distance ridden was } 100 \\
\text { miles? }\end{array}$ \\
\hline 243. S: Um 5 & S2: 5 \\
\hline $\begin{array}{l}\text { 244. T: } 5 . \text { And how did you get that } 5 \text { ? } \\
\text { How did you use the numbers } 100 \text { and } \\
\ldots \text { ? [trails off] }\end{array}$ & $\begin{array}{l}\text { T3: Correct. What math did you do to } \\
\text { get that five? }\end{array}$ \\
\hline $\begin{array}{l}\text { 245. S: } 100 \text { miles divided by miles per } \\
\text { hour. }\end{array}$ & S3: $100 / 20$ \\
\hline $\begin{array}{l}246 . \text { T: So you took the miles and divided } \\
\text { it by } \\
\text { the [garbled, but probably "speed"] }\end{array}$ & $\begin{array}{l}\text { T4: Correct. Now write your answer of } \\
\text { 100/20 using the variables given in the } \\
\text { problem (i.e., put in ' } m \text { ' and 's')? }\end{array}$ \\
\hline $\begin{array}{l}\text { 247. S: Miles divided by 's' plus 'b' equals } \\
\text { time. } \\
\text { [writes } \mathrm{m} / \mathrm{s}+\mathrm{b} \text { ] }\end{array}$ & $\mathrm{S} 4: \mathrm{b}+\mathrm{m} / \mathrm{s}$ \\
\hline 248. T: Right. & T5: Correct. \\
\hline
\end{tabular}

Ms. Lindquist was the first intelligent tutor that had both a model of student thinking and a model of tutorial planning. The system is of the "coached practice" variety that is meant to scaffold "learning by doing" while students practice their problem solving skills. It is different from typical Cognitive Tutors [4] in that it takes its cues more from the dialogs that human tutors have with students and is more flexible in the interactions it has with students. For example, it can acknowledge that part of an 
answer is correct and then engage a student in a "sub dialog" to help him or her to improve the incorrect path. It "breaks" problems down for students by asking questions and re-phrasing questions, but does not give students answers. Whereas Cognitive Tutors typically cover a full-year of algebra, Ms. Lindquist deals only with symbolization problems.

Ms. Lindquist was evaluated in several experiments [13] that showed positive learning results for the ITS. For instance, one analysis focused on 76 middle school students who used Ms. Lindquist as part of a class assignment. The students in the experimental condition received one of Ms. Lindquist's tutorial strategies when they needed help. The students in the control condition were simply told the answer if they answered incorrectly and moved on to the next problem. This experiment controlled for time. The interaction between condition and learning gain was statistically significant with an effect size of 0.56 standard deviations in favor of Ms. Lindquist, even though the students in the control group did significantly fewer problems than those in the experimental group.

Figure 1 shows a screenshot of Ms. Lindquist tutoring a student on a symbolization problem. Ms. Lindquist can be found at algebratutor.org where students and educators can $\log$ in and be tutored on symbolization. Tutoring strategies are randomly chosen for each student.

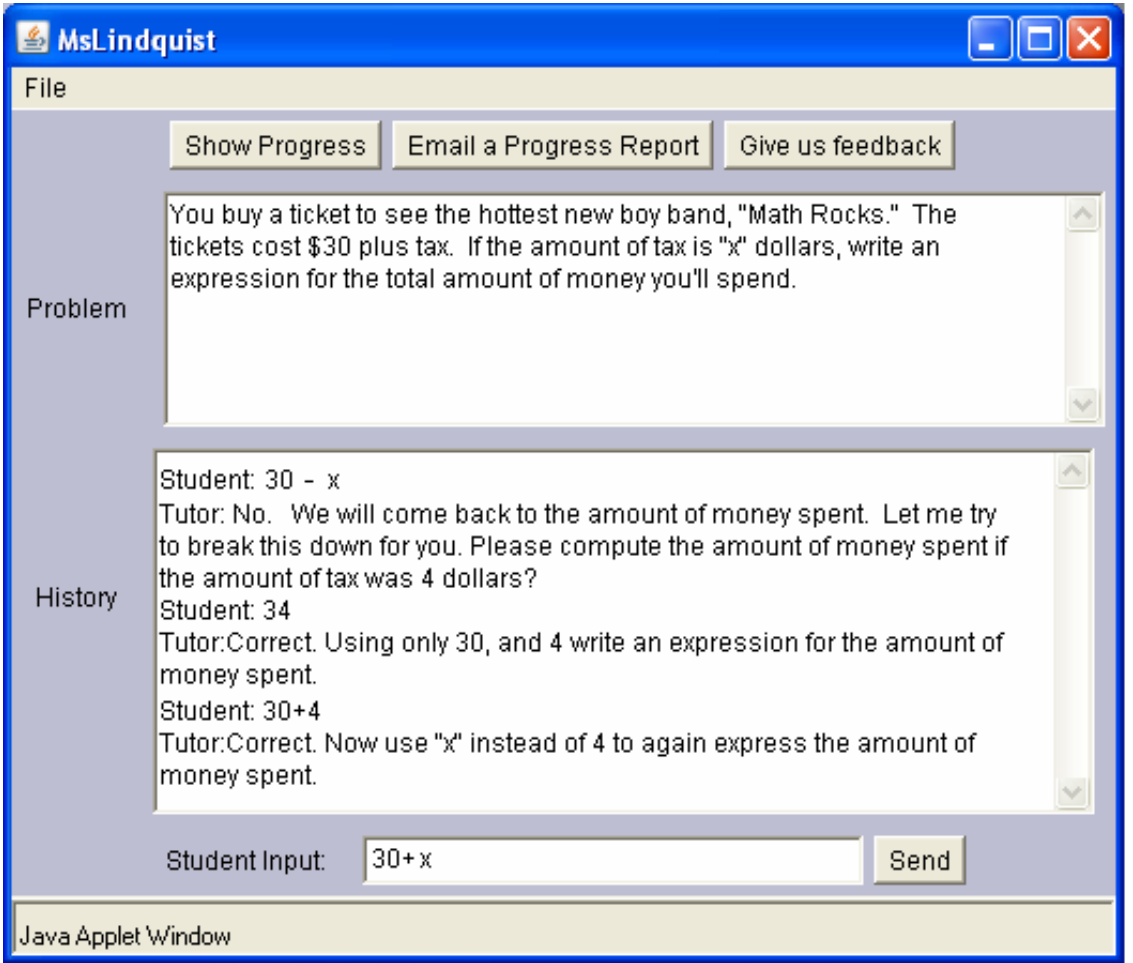

Figure 1. A screenshot of Ms. Lindquist 


\section{Method}

Our research question for this experiment is:

Research question: For students who have Internet connections at home, does 30 minutes of classroom problem-solving do better or worse, in terms of student learning gains than $\sim 30$ minutes of homework problem solving using web-based homework assistance.

Measures of interest included student learning gains measured in school, gains with the computer system itself, time on task, and student reported satisfaction with the computer system.

Setting and Participants. The setting for this study was two regular algebra classrooms in a high school in West Virginia, and students' home computers. Students in both classes were offered extra credit to do the experimental condition as a homework assignment. Obviously, only students with Internet access could participate in the study. 1

Fourteen students from each class agreed to participate in the experimental condition which meant they agreed to work at home, for at least thirty minutes, on the web-based system. Thus, the participants for this study were twenty-eight students (20 female, 8 male, ages 14-16 years) out of a possible 45 students from both classes. All students were classified as typically achieving students; that is, none were identified as learning disabled. The second author taught both classes during the experiment and while he was not the students' regular math teacher, he is a highly qualified, math through Algebra 1, special education teacher and was well-known to the students.

The students had been introduced to the topic of symbolization approximately a month before this study; they were not studying this topic in parallel with the experiment. This topic was chosen because it is the only topic that Ms. Lindquist teaches.

Design. A counterbalanced design was used in which all groups received all conditions, but in a different order. Specifically, one group participated in the classwork condition first while the other group participated in the homework condition first, thus ensuring a different sequence of instruction for each group.

A pretest was administered to both groups to ensure initial comparability on the dependent measures. The students were given a mid-test after participating in the first condition (according to which group they were in) and a post-test after completion of the experiment. The data for this study were analyzed using SPSS. Analysis of Variance, t-tests and descriptive tests were used. Table 2 displays the overall design of the study.

\footnotetext{
${ }^{1}$ This was not a planned circumstance, as the original plan was to have students use computer labs in school. However, because the school recently installed new security software that prevented the web site from functioning correctly, the instructor instead sought volunteers to engage in the computer condition at home for extra class credit. Unfortunately, this excluded students who did not have internet at home from the study.
} 
Table 2. Overall experimental design

\begin{tabular}{|c|c|c|c|}
\hline Day & Time & Group 1 & Group 2 \\
\hline $\mathbf{1}$ & $\begin{array}{c}\sim 10-20 \\
\text { minutes }\end{array}$ & $\begin{array}{c}\text { Pretest / Introduction to } \\
\text { Computer-system }\end{array}$ & $\begin{array}{c}\text { Pretest / Introduction to } \\
\text { Computer-system }\end{array}$ \\
\hline $\mathbf{2}$ & 30 minutes & Classwork & $\begin{array}{c}\text { Web-based } \\
\text { Homework }\end{array}$ \\
\hline $\mathbf{3}$ & $\begin{array}{c}\sim 10-15 \\
\text { minutes }\end{array}$ & Mid test & Mid test \\
\hline $\mathbf{4}$ & 30 minutes & $\begin{array}{c}\text { Web-based } \\
\text { Homework }\end{array}$ & Classwork \\
\hline $\mathbf{5}$ & $\begin{array}{c}\sim 10-15 \\
\text { minutes }\end{array}$ & Post-test & Post-test \\
\hline
\end{tabular}

Procedures. The study was conducted over a five day period and included a pretest, mid-test, and post-test administered on days one, three and five of the experiment, before and after each condition. The pretest, mid-test and post-test all contained the same nine problems and were administered on paper. The questions on these tests were symbolization problems similar to those worked on in the classwork and homework conditions. The following problems are samples of those that appeared on these tests:

1) Mary starts a car washing business at the local gas station. She spends $\$ 30$ to buy supplies. She then charges $\$ 10$ to wash a car and scrub clean all four tires. Write an expression showing how much money she has made after she has washed "c" cars.

2) Mary's mom bought her a CD player that cost $\$ 200$. She has to pay her mom $\$ 15$ per month until it is paid off. Write an expression for the amount she owes her mom after " $n$ " months.

3) Martin got a Christmas bonus at work that was worth 'b' dollars. He first paid the rent which was ' $r$ ' dollars. He then split the remaining money between his three children. How much money did each child get?

The experimental conditions occurred on days two and four in a counterbalanced manner. Group 1 participated in the classwork condition on day two and did the homework condition on day four, while Group 2 did the homework condition on day two and the classwork condition on day four. For the homework condition both groups were taught how to create an account and log on to the system and were instructed to spend at least thirty minutes on the computer system from the time they were logged on without stopping.

To be clear, students who did not volunteer to do the extra homework were not in the classroom; students who did volunteer to do the extra homework required were "pulled out" of their normal classroom for the classwork part of this experiment. Obviously, this was a more motivated group of students. 
The classwork activities were divided into two main parts: 1) introduction with inclass examples, and 2) guided practice. Students were given a worksheet with twentyfive problems. The instructor demonstrated how to translate word problems into algebraic expressions by first displaying problems on an overhead projector and reading the problems to the class. The instructor then discussed several traditional textbook methods used to translate word problems to algebraic expressions including matching "clue" words with mathematical operations and procedures and using problem-solving plans such as: explore the problem, plan the solution, solve the problem, and examine the solution. The instructor demonstrated five problems that took approximately twenty minutes. During the remaining thirty minutes of the class, students completed their worksheets and the instructor was available to all students and assisted them in the order in which students requested help. The students did not get feedback on every problem and those who did not request help got no feedback at all. Some of the problems in the worksheet are as follows:

1) Missy starts a business selling fishing bait. She spends $\$ 40$ buying supplies like containers, bags, and minnows. She sells a container of bait for $\$ 3$. If she sells "c" containers of bait, how much profit will she end up making?

2) Aunt Bee won "d" dollars in the lottery. She spent $\$ 40$ on groceries and spilt the rest up in presents for her six children. How much did each child get?

3) Jane is " $\mathrm{j}$ " years old. Peg is "p; years old. Mary is Peg's age minus Tom's age. Tom is 4 years younger than Jane. Peg is " $x$ " years older than

Mark. Write an expression for Mary's age.

Students in the homework condition were asked to log in to Ms. Lindquist and work for at least 30 minutes on symbolization problems. However, this experiment does not control for time since we could not control how much time students spent on their homework.

\section{Results}

We assume that the groups were fairly balanced since we found no statistically significant difference $(\mathrm{t}=-0.655, \mathrm{p}<0.518)$ at pretest between groups. The mean pretest score for the computer first group was $(\mathrm{m}=3.86$, $\mathrm{sd}=1.29)$ and for the computer second group, the mean pretest score was $(\mathrm{m}=4.21$, $\mathrm{sd}=1.58)$.

Overall, students showed large learning gains $(\mathrm{F}=6.58, \mathrm{p}<0.016)$ as measured by repeated-measures ANOVA. For both groups, we looked to see if the pretest to post-test gains were reliably different from zero, and in both cases they were, suggesting that students learned from doing classwork and from doing web-based homework. 
When comparing web-based homework gains and classwork gains, we found statistically significant differences $(\mathrm{t}=2.044, \mathrm{p}=0.051)$ in favor of the web-based homework condition $(\mathrm{m}=1.41$, $\mathrm{sd}=1.00)$ over the classwork condition $(\mathrm{m}=0.8707$, $\mathrm{sd}=0.80$ ), suggesting that students achieved a one-half problem learning gain from the computer condition overall. The effect size for this difference was 0.54 with confidence intervals of $-0.12-0.94$. We ignore the order in which students participated in each condition in this analysis (the order of condition is considered in the next analysis shown in Table 4). The results of this analysis are summarized in Table 3.

Table 3. Summary of results of comparing classwork to web-based homework

\begin{tabular}{|c|c|c|c|c|}
\hline $\mathrm{N}$ & $\begin{array}{c}\text { effect } \\
\text { size }\end{array}$ & $\mathrm{p}$ value & $\begin{array}{c}\text { Mean classwork gain } \\
\text { score }\end{array}$ & $\begin{array}{c}\text { Mean homework gain } \\
\text { score }\end{array}$ \\
\hline 28 & 0.54 & 0.051 & 0.8707 & 1.41 \\
\hline
\end{tabular}

Finally, we looked to see if there was a difference in learning gains when taking into account the binary factors of order and computer condition. We found that for both groups (computer first and computer second) the difference was not statistically significantly different $(\mathrm{F}=2.508, \mathrm{p}<0.126)$. These results are summarized in Table 4.

Table 4. The Average Learning Gain split out by whether the students did the web-based homework first or second. (Dependent Variable: Computer Gain)

\begin{tabular}{|c|c|c|c|}
\hline Group & $\mathbf{N}$ & Mean & Standard Deviation \\
\hline Overall & 28 & 1.3571 & 1.0261 \\
\hline Computer first & 14 & 1.5000 & 0.94054 \\
\hline Computer second & 14 & 1.2143 & 1.1217 \\
\hline
\end{tabular}

Anecdotal Data on Motivation: Students were directed to work for at least 30 minutes on the web-based homework, however some of the computer log files were lost due to technical difficulties, so we were not able to determine whether all students did their homework or not. We were able to recover $70 \%$ of the log files and we have no reason to believe that the files that were lost would differ greatly from those recovered. From the recovered log files, we could see that students worked for an average of 25 minutes on Ms. Lindquist. Four students worked for over 30 minutes, one student for an hour and twenty minutes. We hoped that the students would be motivated and want to spend more time on the computer doing their homework and some did. However, the average time spent by both groups on problem-solving seems comparable and the classwork condition actually spent more time overall when we count the time spent by the instructor at the beginning of the class on the introduction and symbolization examples (50 minutes total).

There was evidence that students had a positive attitude toward the tutoring dialog and also thought it was helpful. For example, students were asked to respond to the following questions embedded within the computer-delivered instruction: 
1) "Rate from 1-10 how much trouble you had on this section. Use 1 for easy and 10 for hard."

2) "Did you find the computer-delivered instruction helpful?"

3) "Before you quit, would you please give us feedback on Ms. Lindquist. Type your feedback anywhere in this window".

All but three students who did the web-based homework answered "yes" they thought the feedback was helpful and gave an average difficulty rating of 3.3. Several students answered question three with the following comments:

1) "I think this is a good program to help students in math and he helps them understand it better",

2) "It was fun and helped me understand it better",

3) "This program is a very good way to tutor people about algebra, but even though it tells you what you have done wrong it sometimes becomes frustrating therefore it may be a good idea to have the student write questions about specific problems that they may have because an actual person helping is always better than a computer program"

4) "This program is a significant program in teaching algebra. Some problems are difficult, but are possible to figure out".

\section{Discussion}

In this experiment, we found that students in both classwork and web-based homework conditions had learning gains between pre- mid- and post-tests. The webbased homework condition outperformed the classwork condition with an effect size of 0.54. Given that students in the web-based homework condition learned more than students doing problem-solving practice in class, perhaps the ITS might well be beneficial in the context of assigned homework. However, we are not sure if our results are due to better "intelligent" pedagogy or to students receiving immediate feedback on their work.

We speculate that our results might be affected by the fact that we asked students to volunteer for this experiment and do extra credit work at home making this experiment's population probably more motivated (as indicated by being willing to do extra-credit work at home). Our results could also be affected by the fact that only students with access to computers and internet at home could participate in this experiment.

Some states in the U.S., such as Virginia, Maine, and Indiana are implementing "one-to-one computing" programs [14] in schools where each child gets his/her own laptop to use during school and sometimes they are allowed to take the laptops home, as well. In fact, the Maine Learning Technology Initiative (2002-2004) supplied every seventh and eighth grade student in Maine and their teachers with laptop computers, allowing $40 \%$ of the middle schools students to take their laptops home. While we await research studies on the effects of one-to-one computing on teaching and learning we have seen reports that students in one-to-one computing programs are 
more engaged, motivated and interact better with teachers [15, 16]. At the same time, widely published opposition cites the high cost, potential access to inappropriate material and lack of proven impact on student achievement $[17,18]$ as reasons to abandon one-to-one computing programs in schools. Even so, the numbers of U.S. schools that are adopting one-to-one computing programs continue to increase every year [18].

As the digital divide narrows and more states become committed to one-to-one computing programs, opportunities for students to do their homework online increase. We conducted another study comparing web-based math homework to paper-andpencil math homework for fifth grade students which also showed favorable results for the web-based homework condition [19]. We think that implications of these studies, and others like them could be important to policy- makers, when considering whether to adopt one-to-one computing programs (especially considering the falling price of laptops and claims that they can now be produced for prices as low as $\$ 200$ each [20].)

Future Work. We believe that the results of this study may be affected by the fact that only some students could participate either because of the motivation to earn extra credit or because they did not have access to the web-based ITS. For future work, we would like to repeat this study with more students that are not limited to having computers and internet at home. To counter this, we would direct students who do not have computers at home to use the computers in the library or the school's computer lab after school. This way we would also be able to see if we could get similar results with students who are not as motivated as the students in this study were by requiring that all students in the class participate by doing their homework using a web-based ITS.

\section{References}

1. Kulik, C. C. \& Kulik, J. A. (1991) Effectiveness of Computer-Based Instruction: An Updated Analysis. Computers in Human Behavior 7, 75-94.

2. Kulik, J.A. (1994) Meta-Analytic Studies of Findings on Computer-Based Instruction. In Technology Assessment in Education and Training, (E. L. Baker \& H. F. O'Neil, Jr., eds.), pp. 9-33, Erlbaum Associates, Hillsdale, NJ.

3. Anderson, J. R., Corbett, A., Koedinger, K., \& Pelletier, R. (1995) Cognitive Tutors: Lessons Learned. Journal of the Learning Sciences 4(2), 167-207.

4. Koedinger, K. R., Anderson, J. R., Hadley, W. H. \& Mark, M. A. (1997) Intelligent tutoring goes to school in the big city. In Proceedings of the $7^{\text {th }}$ World Conference on Artificial Intelligence in Education, pp. 421-428, Association for the Advancement of Computing in Education, Charlottesville, VA.

5. VanLehn, K., Lynch, C., Schulze, K. Shapiro, J. A., Shelby, R., Taylor, L., Treacy, D.,Weinstein, A., \& Wintersgill, M. (2005) The Andes physics tutoring system: Lessons Learned. In International Journal of Artificial Intelligence and Education, 15 (3), 1-47.

6. Carroll, J. M., \& Kay, D. S. (1988) Prompting, feedback and error correction in the design of a scenario machine. International Journal of Man-Machine Studies 28, 11-27. 
7. Corbett, A., \& Anderson, J. R. (2001) Locus of feedback control in computer-based tutoring: Impact on learning rate, achievement and attitudes. In Proceedings of ACM CHI 2001 Conference on Human Factors in Computing Systems (J. Jacko, A. Sears, M. Beaudouin-Lafon \& R. Jacob, eds.), pp. 245-252, ACM Press, New York.

8. Mathan, S. \& Koedinger, K. R. (2003). Recasting the feedback debate: Benefits of tutoring error detection and correction skills. In Hoppe, Verdejo, \& Kay (Eds.), Artificial Intelligence in Education, Proceedings of AI-ED 2003 (pp. 13-18). Amsterdam, IOS Press.

9. Heffernan, N. T., \& Koedinger, K. R., (2002) An Intelligent Tutoring System Incorporating a Model of an Experienced Human Tutor. International Conference on Intelligent Tutoring System 2002. Biarritz, France, 596-608.

10. Warnakulasooriya, R. \& Pritchard, D. E. (2005) Learning and problem-solving transfer between physics problems using web-based homework tutor. Conference Proceedings: EdMedia -World Conference on Educational Multimedia, Hypermedia \& Telecommunications. Vol. 2005, 2976-2983.

11. Pascarella, A. M. (2002). CAPA (Computer-Assisted Personalized Assignments) in a Large University Setting. Unpublished Doctoral Dissertation, University of Colorado, Boulder, CO.

12. Bonham, S. W., Deardorff, D. L., \& Beichner, R. J. (2003). Comparison of student performance using web and paper-based homework in college-level physics. Journal of Research in Science Teaching, 40(10), 1050-1071.

13. Heffernan, N. T. \& Croteau, E. (2004). Web-Based Evaluations Showing Differential Learning for Tutorial Strategies Employed by the Ms. Lindquist Tutor. In James C. Lester, Rosa Maria Vicari, Fábio Paraguaçu (Eds.) Proceedings of 7th Annual Intelligent Tutoring Systems Conference, Maceio, Brazil. Springer Lecture Notes in Computer Science. pp. 491-500.

14. Bonifaz, A., \& Zucker, A. A. (2004). Lessons learned about providing laptops for all students. Newton, MA: Education Development Center. Retrieved October 15, 2007 from http://www.neirtec.org/laptop.

15. Silvernail, D. L., \& Lane, D. M. M. (2004). The impact of Maine's one-to-one laptop program on middle school teachers and students (Report \#1). Gorham, ME: Maine Education Policy Research Institute, University of Southern Maine Office.

16. Bebell, D. (2005, May) "Technology promoting student excellence: an investigation of the $1^{\text {st }}$ year of 1:1 computing in New Hampshire middle schools". Technology and Assessment Study Collaborative. Retrieved November 20, 2007 from www.intasc.org

17. Vascellaro, J. E., (2006, August 31) Saying no to school laptops. The Wall Street Journal. $\begin{array}{llll}\text { Retrieved November } & 20, & 2007 & \text { from }\end{array}$ http://online.wsj.com/article_email/SB115698378733250090IMyQjAxMDE2NTM2MTkzODEzWj.html

18. Hu, W. (2007, May 4) Seeing No Progress, Some Schools Drop Laptops. New York Times. $\begin{array}{llll}\text { Retrieved } & \text { November } & 25, & \end{array}$ http://www.nytimes.com/2007/05/04/education/04laptop.html

19. Mendicino, M., Razzaq, L. \& Heffernan, N. T. A Comparison of Traditional Homework with Computer Supported Homework. Journal of Research on Technology in Education. Accepted.

20. Bray, H. (2007, November 19) \$100 laptops? Not really, but $\$ 200$ isn't bad. Boston Globe, Retrieved November 20, 2007 from http://www.boston.com/business/technology/articles/2007/11/19/100_laptops_not_really_ but_200_isnt_bad/ 